\title{
HOT TEARING IN DIRECTIONALLY SOLIDIFIED NI-BASED SUPERALLOYS
}

\author{
Jian Zhang ${ }^{1,2}$ \\ ${ }^{1}$ Superalloys Division, Institute of Metal Research, Chinese Academy of Sciences, Shenyang 110016, China \\ ${ }^{2}$ WTM Institute, Department of Materials Science, University of Erlangen-Nürnberg, 91058 Erlangen, Germany
}

Keywords: Directional solidification, Hot tearing, Ni-based superalloys

\begin{abstract}
The hot tearing mechanism has been studied in directionally solidified (DS) Ni-based superalloys with columnar grain structures. Castability tests and optical metallography of quenched samples were employed to explore the effect of microstructural evolution, grain boundary characteristics on the susceptibility of hot cracking formation during DS. Gleeble tests were performed on DS samples at temperatures above the solidus. The effect of major alloying elements, such as Ti, Ta and $\mathrm{Hf}$, as well as minor elements, such as $\mathrm{Zr}$ and $\mathrm{B}$, has been examined. It is found that in most of the Ni-based superalloys studied there exists a critical temperature range $\Delta T_{C T R}$, within which any opening of the grain boundary during DS can hardly be compensated for by feeding of liquid due to the high solid fraction. Significant change of the liquid fraction within $\Delta T_{C T R}$ resulted in bad castability. Dramatic influence of the interaction of $\mathrm{Zr}$ and $\mathrm{B}$ on the hot tearing susceptibility was also found, with the effect being particularly strong if $\mathrm{Zr}$ concentration was high. The present results lead to two factors influence the hot tearing susceptibility within $\Delta T_{C T R}$ : (1) the strains and strain rates developed; and (2) the grain boundary cohesion. High strains and strain rates promote hot tearing, while stronger solid skeleton resulted from more bridging of the secondary dendrite arms generally leads to better hot tearing resistance.
\end{abstract}

\section{Introduction}

Cracking of superalloys during cooling from the casting temperature in directional solidification (DS) is a well-known problem in the casting industry. The cracks form along the boundaries between the columnar grains in the last stages of the DS process.

Practically, the most common solution for the problem of hot tearing in Ni-based superalloys is compositional modification by addition of Hf [1-3]. However, a number of detrimental effects were found when Hf was added: (1) Hf is a reactive element that may cause reactions with the mould and formation of brittle Hf containing inclusions; (2) Hf lowers the incipient melting point and thus the solutionizing temperature which limits the possibility to homogenize the alloy and to dissolve coarse $\gamma^{\prime}$ precipitates. Consequently, DS alloys containing Hf show little or no strength advantage at all compared with the same alloy without $\mathrm{Hf}$ modification in the equiaxed condition. It is of particular interest, therefore, to study the mechanism of hot tearing and to try to improve hot tearing resistance of superalloys without additions of Hf $[1,4]$.

Theoretically, hot tearing as a source for bad castability has been studied extensively during the past decades $[5,6]$. It is generally believed that: (1) Hot tearing occurs in a so-called "film stage" at the final stages of solidification where the residual liquid is still more or less continuous. Feeding in this stage is difficult; (2) Hot tearing is a grain boundary (GB) phenomenon: the initiation and/or propagation of hot cracks are usually intergranular [7-9]. In case of a DS process where cracks develop along the broad faces of columnar grains, this means that only small cohesion forces are developed, essentially by bridging of secondary dendrite arms. If this little resistance is overcome by tensile forces and the grains are pulled apart, hot tearing can hardly be prevented by feeding of melt over long distances through narrow channels.

The present study is mainly focused on the commercial Ni-based superalloy IN792 (in a Hf free modification) that shows excellent corrosion resistance but poor castability. The aim of this research program is to understand the cracking mechanisms and develop new alloy compositions that are less susceptible to cracking. Alloys such as CM247 that exhibit excellent castability were chosen as reference materials.

\section{Materials and experimental}

The nominal compositions of the alloys used in the experiments are listed in Table I. (All data given are in weight percent.) The content of contaminants was very low. For example, the content of sulfur was found to be less than 10ppm in the DS castings.

Tube-shaped specimens with a wall thickness of $2.5 \mathrm{~mm}, 2 \mathrm{~mm}$, or $1.5 \mathrm{~mm}$ were cast to evaluate the cracking susceptibility. Castability tests were carried out in moulds comprising an outer ceramic tube serving as an outer shell and an inner ceramic tube serving as a core. The alloys were solidified by a withdrawal method. Castability of an alloy was then evaluated by measuring a crack ratio $r$ defined as $r=\sum_{i=1}^{n} l_{i} w_{i} / L C$, where $n$ is the number of the cracks, $l_{i}$ and $w_{i}$ are the length and maximum width of a crack, respectively, and $L$ is the length of the cast tube, $C$ the outer circumference of the tube.

Single crystal seeds from superalloy PWA1483 (composition listed in Table I) were used to produce IN792 tube castings with single crystal or bi-crystal structures. The GB misorientation between two grains can be described by the angle of rotation around the [001] axis, $\alpha$. $\alpha$ in selected tube castings were measured by using X-ray Laue method and by optical microscopy from secondary dendrite arm orientation.

Differential scanning calorimetry (DSC) measurements were performed in a Netzsch testing apparatus (model STA 409), using heating and cooling rates of $5{ }^{\circ} \mathrm{C} / \mathrm{min}$. The data obtained on cooling were used to determine the liquidus and solidus temperatures.

An attempt of testing the strength of the semi-solid DS skeleton was performed by using a Gleeble 1500 thermo-mechanical testing machine. DS specimens with or without $\mathrm{Zr}$ and B content were arranged in the vacuum chamber and tensile tests were performed perpendicular to the columnar GBs. 
Table I. Compositions of Commercial Alloys Used in the Present Experiments

\begin{tabular}{|c|c|c|c|c|c|c|c|c|c|c|c|c|}
\hline Alloy & Cr & Co & Mo & W & Al & Ti & Ta & B & Zr & C & Hf & Ni \\
\hline IN792 & 12.4 & 9.2 & 1.9 & 3.9 & 3.5 & 3.9 & 4.2 & 0.016 & 0.018 & 0.07 & 0 & Bal. \\
\hline CM247 & 8.0 & 9.4 & 0.5 & 9.5 & 5.7 & 0.7 & 3.2 & 0.017 & 0.018 & 0.07 & 1.5 & Bal. \\
\hline PWA1483 & 12.2 & 9.2 & 1.9 & 3.8 & 3.6 & 4.2 & 5.0 & 0 & 0 & 0.07 & 0 & Bal. \\
\hline
\end{tabular}

Quenching experiments were made in selected samples to freeze the microstructure at different temperatures during solidification. Samples were prepared in the usual way for metallographic examination. Optical microscopy and scanning electron microscopy (SEM) were employed to observe the microstructure. Phase fraction was measured by an image analyzer. Details of the experimental procedure were given elsewhere [10-13].

\section{Results}

\section{$\underline{\mathrm{DSC}}$}

Typical DSC curves during cooling are shown in Fig. 1. Three major phase transformations can be detected: the solidification of $\gamma$ primary phase, followed by carbide formation, and the final formation of $\gamma / \gamma^{\prime}$ in interdendritic areas. The change of liquid fraction during solidification of IN792 and CM247 obtained by quenching experiments is shown in Fig. 2. The results indicate that the liquid fraction decreases rapidly at the beginning of solidification. After formation of carbides, the liquid fraction decreases slowly. Selected DSC data was listed in Table II. One can see that neither the total freezing range $\Delta T$ nor the $\Delta T_{C T R}$ (critical temperature range, see the discussion section) can be related to the castability of an alloy when referring to Fig. 3.

Table II. Phase Formation Temperatures $\left({ }^{\circ} \mathrm{C}\right)$ Measured from DSC in Some Experimental Alloys at $5{ }^{\circ} \mathrm{C} / \mathrm{min}$ during Cooling*

\begin{tabular}{cccccc}
\hline Alloy & $\mathrm{T}_{\gamma}$ & $\mathrm{T}_{\mathrm{C}}$ & $\mathrm{T}_{\gamma / \gamma^{\prime}}$ & $\Delta \mathrm{T}$ & $\Delta \mathrm{T}_{\mathrm{CTR}}$ \\
\hline IN792 & 1339 & 1315 & 1245 & 94 & 70 \\
\hline IN792Ti2 & 1386 & - & - & -- & -- \\
\hline IN792Ti3 & 1323 & 1305 & 1251 & 72 & 54 \\
\hline IN792Ti4.5 & 1338 & 1302 & 1250 & 88 & 52 \\
\hline IN792Hf1 & 1338 & 1309 & 1239 & 99 & 70 \\
\hline IN792Hf2 & 1329 & 1305 & 1236 & 93 & 69 \\
\hline IN792Ti3Ta5 & 1357 & 1309 & - & -- & -- \\
\hline IN792Ti3Ta2.5 & 1365 & - & - & -- & -- \\
\hline CM247 & 1384 & 1342 & 1268 & 116 & 74 \\
\hline$* T_{p} T_{C}$ and $T_{\gamma / \gamma^{\prime}}$ is the temperature where $\gamma$, carbide and \\
$\gamma / \gamma^{\prime}$ begin to form, respectively. $\Delta T:$ total freezing range \\
and $\Delta T_{C T R}=T_{C}-T_{\gamma / \gamma^{\prime}}$. The experimental alloys listed also \\
indicate the modified elements. For example, IN792Ti2 \\
represents an alloy with standard IN792 composition \\
but with 2\% Ti. Temperatures not detectable by DSC \\
were marked as “-".
\end{tabular}

\section{$\underline{\text { Castability tests }}$}

The selected results of castability tests are shown in Fig. 3. It clearly demonstrates that: (1) Increasing Ti content reduces the hot tearing resistance of IN792 dramatically; (2) Castability has been improved impressively when carbon is removed from IN792; (3) IN792 tube castings display severe cracks, while CM247 generally results in crack free castings; (4) Hf improves the castability. The IN792 with Hf addition shows no hot tearing,

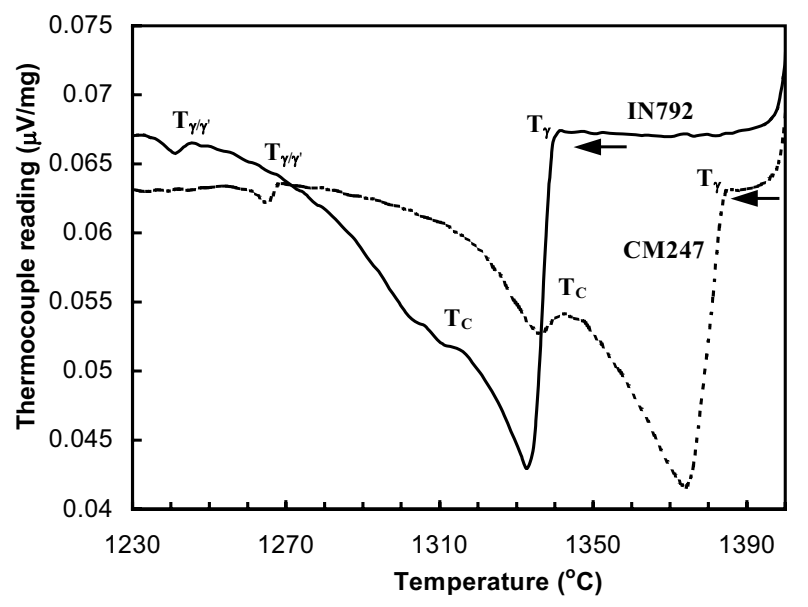

Figure 1. Typical DSC curves obtained from IN792 and CM247 cooling at $5^{\circ} \mathrm{C} / \mathrm{min}$.

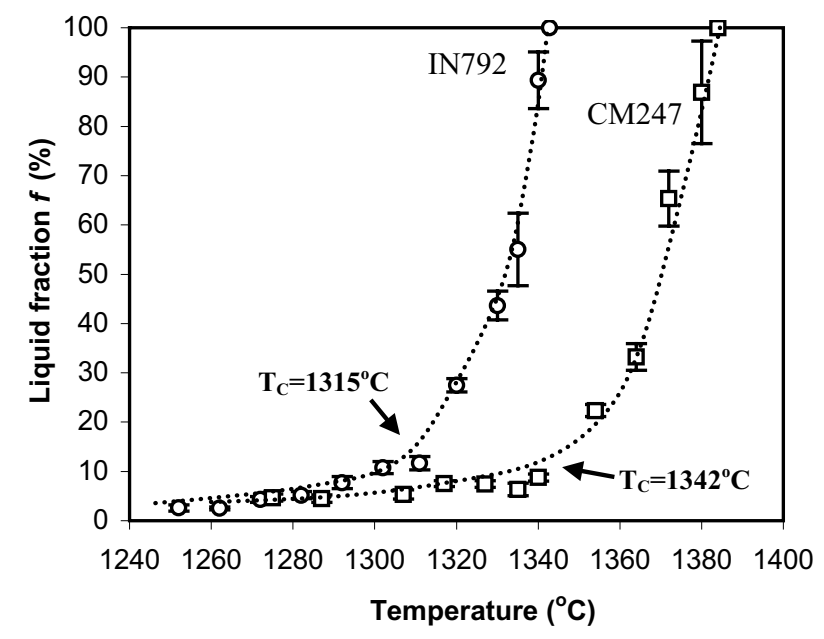

Figure 2. Liquid fraction change as a function of temperature in IN792 and CM247 during solidification.

while Hf free CM247 results in severe cracks; (5) When Ti content is slightly lowered, increasing or decreasing Ta content in IN792 also improves the castability. Fig. 3 also demonstrates that the present experimental setup and method of data analysis allow evaluating the castability of Ni-based superalloys reliably.

The castability of IN792 single crystal (SC) and bi-crystal (BC) specimens is summarized in Fig. 4 [13]. No hot tearing is observed with SC structure. Crack free castings are also obtained when the GB misorientation angle is less than $\sim 12^{\circ}$. Small cracks are observed when the GB angle increases further to $\sim 15^{\circ}$. A GB misorientation over $25^{\circ}$ leads to bad castability, i.e. formation of large cracks. (Occasional stray grains were noted at the surface in $\mathrm{SC}$ and $\mathrm{BC}$ castings. It is assumed that they do not influence the 


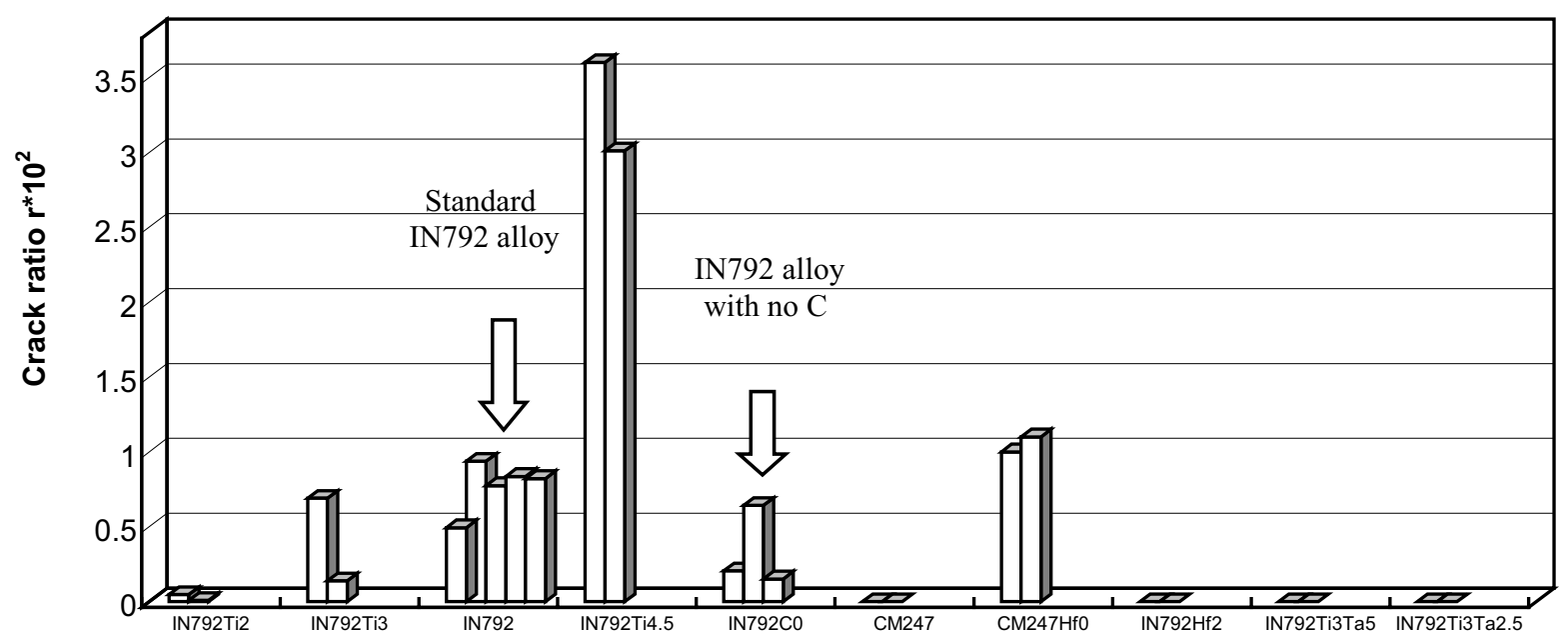

Figure 3. Selected results from castability tests. Each bar represents one casting trial.

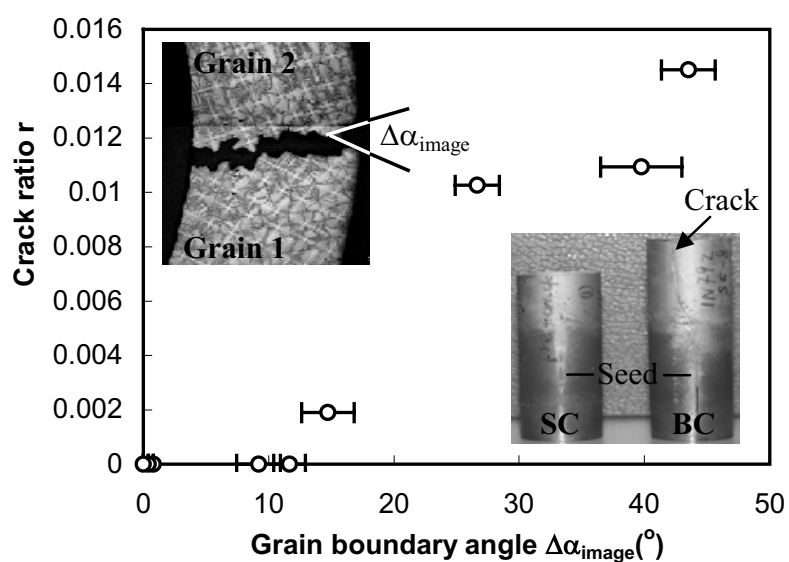

Figure 4. Effect of grain boundary misorientation on castability. GB misorientation measured from X-ray Laue method and image analyzer shows good agreement.

castability results shown in Fig. 4 since GBs of these grains do not reach across the entire wall of the tube castings.)

\section{Quenching experiments}

As one can see in the discussion section, the critical temperature range $\left(\Delta T_{C T R}\right)$ for hot tearing to occur corresponds to the lower end of the freezing range, i.e. approximately from carbide formation temperature $T_{C}$ to the $\gamma / \gamma^{\prime}$ formation temperature $T_{\gamma / \gamma}$. Therefore, the microstructural evolution of some experimental alloys was studied in detail within the $\Delta T_{C T R}$. Comparing with Fig. 3 , one can see from Fig. 5 that the liquid volume fraction of the alloys IN792Ti3, IN792 and IN792Ti4.5, which have bad castability, changed much more strongly with temperature than that of the other alloys studied, which have good castability. The approximate slope for the curves $(d f / d T)$ is also indicated in the diagram.

\section{Effect of minor alloying elements}
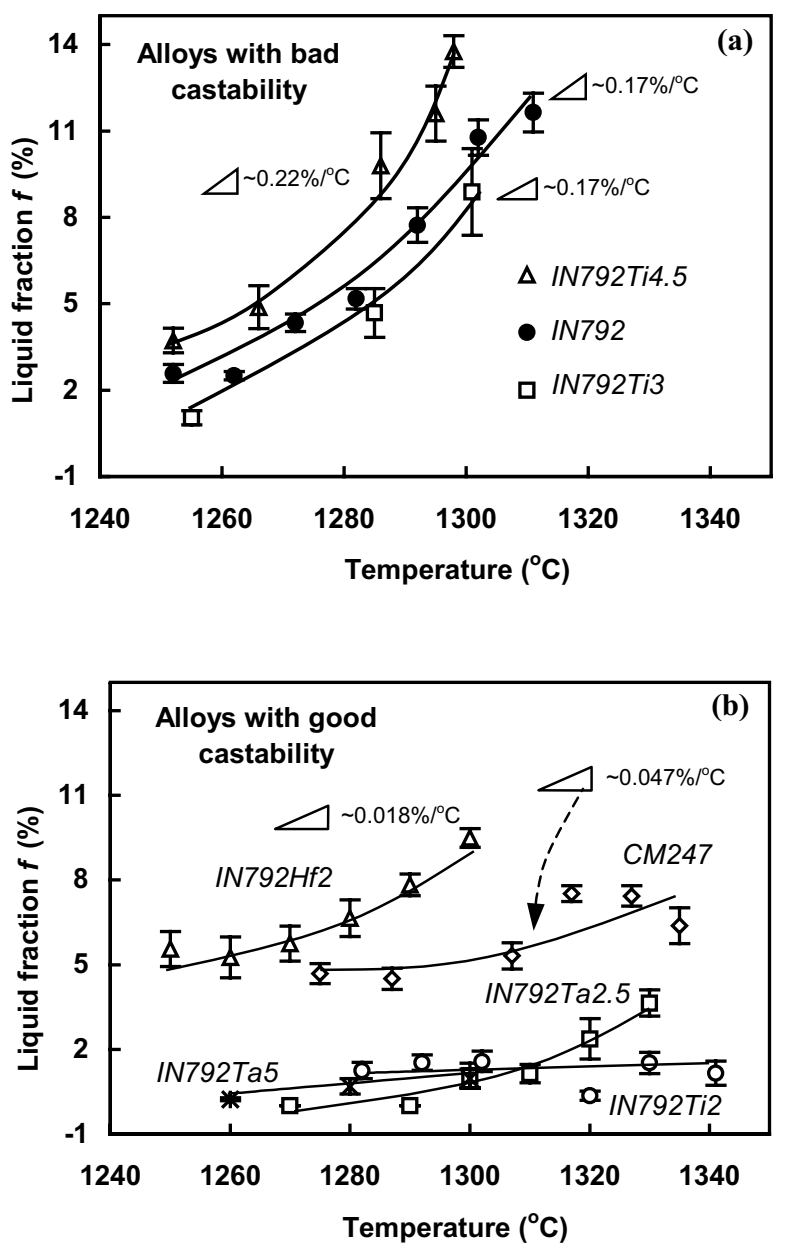

Figure 5. Liquid fraction as a function of temperature in different alloys. Temperature interval investigated is within $\Delta T_{C T R}$. (a) Alloys with bad castability showing large change of liquid fraction as temperature drops, and (b) alloys with good castability showing a much gradual change of liquid fraction. 
Castability of some experimental alloys with different $\mathrm{B}$ and $\mathrm{Zr}$ content is shown in Fig. 6 [12]. In Fig. 6 (a), castability of alloys containing $\mathrm{Zr}$ ranging from 0 to $\sim 500 \mathrm{ppm}$, and $\mathrm{B}$ ranging from 0 to $\sim 550 \mathrm{ppm}$ have been tested by casting samples with a wall thickness of $2 \mathrm{~mm}$. The master alloy without any $\mathrm{Zr}$ and $\mathrm{B}$ generally exhibits good castability. In the alloys without B content $(<10 \mathrm{ppm})$, increasing $\mathrm{Zr}$ content does not lead to bad castability. Crack free castings can be obtained even after increasing $\mathrm{Zr}$ content to $480 \mathrm{ppm}$. Similarly, without $\mathrm{Zr}$ content $(<70 \mathrm{ppm})$, increasing $\mathrm{B}$ content does not result in bad castability either. Crack free castings can be obtained when B content is as high as 560ppm. When both $\mathrm{Zr}$ and $\mathrm{B}$ exist in the alloy at relatively low concentration, the hot tearing sensitivity of the alloy is still low. However, a further increase of $\mathrm{Zr}$ shows a significant detrimental effect on castability of the alloys, even when B content is kept at a relatively low level, i.e. $<150 \mathrm{ppm}$.

Based on this information, further castability trials were performed in a narrower range of $\mathrm{Zr}$ and $\mathrm{B}$ concentrations: $\mathrm{Zr}$ ranging approximately from $150 \mathrm{ppm}$ to $400 \mathrm{ppm}$, and $\mathrm{B}$ ranging approximately from 100 to $300 \mathrm{ppm}$. Specimens with thinner wall thickness $(1.5 \mathrm{~mm})$ were used in these tests. The results are shown in Fig. 6 (b). A similar trend as above is observed. When $\mathrm{Zr}$ and B contents are low, the alloy is not prone to hot tearing, as expected. At medium high $\mathrm{B}$ content, increasing $\mathrm{Zr}$ significantly promotes the hot tearing susceptibility of the alloys. On the other hand, at medium high $\mathrm{Zr}$ content, increasing B only slightly increases the hot tearing sensitivity of the alloys.

To get more insight into the effect of minor elements, Gleeble tests were performed on DS samples at temperatures above the solidus of IN792. Two alloys (IN792 master heats without Zr and B, and IN792 alloy with 200ppm Zr and 200ppm B) were DS cast at a withdrawal speed of $7 \mathrm{~mm} / \mathrm{min}$. The primary dendrite arm spacing of the DS castings was measured as $\sim 500 \mu \mathrm{m}$. Tensile direction in Gleeble testing was arranged to be perpendicular to the DS grain boundaries. The preliminary results were compared in Fig. 7. It seems that stronger GB cohesion was achieved in $\mathrm{Zr}$ and $\mathrm{B}$ free alloy at high temperature. Moreover, the $\mathrm{Zr}$ and $\mathrm{B}$ containing alloy seems to lose the strength at lower temperature compared with the $\mathrm{Zr}$ and B free alloy. Since the strength at this high temperature is low, modification of the testing method such as the special spring mechanism mentioned in [1] should be considered in future tests for obtaining precise data.

Table III summaries the phase formation temperatures detected by DSC in different alloys. Again, one can see that neither the total freezing range $\Delta T$ nor the critical temperature range $\Delta T_{C T R}$ can be related to the hot tearing susceptibility of the alloys studied. Another interesting finding is that $\mathrm{B}$ significantly promotes the formation of coarse $\gamma / \gamma^{\prime}$ in interdendritic areas and decreases the solidus temperature. On the other hand, $\mathrm{Zr}$ does not affect the fraction of coarse interdendritic $\gamma / \gamma^{\prime}$ and shows little influence on the solidus temperature [12].

\section{Discussion}

\section{Critical temperature range}

The nil strength temperature has been determined as $1322{ }^{\circ} \mathrm{C}$ for DS CM247, and $1291{ }^{\circ} \mathrm{C}$ for DS IN792, respectively [1]. One can see from Fig. 2 that these temperatures are close to, but somewhat below the formation temperatures of carbides in both alloys. Castability tests also indicate that interdendritic carbides increase the hot tearing susceptibility probably by blocking the feeding channels during solidification (Fig. 3). Therefore, the critical temperature range $\Delta T_{C T R}$ for hot tearing during DS is inferred as: $\Delta T_{C T R}=T_{C}-T_{\gamma / \gamma}$. At temperature above $T_{C}$, mass feeding is possible, i.e. any opening at the interdendritic region can probably be compensated for by liquid from the upper region of the mush. At temperature below $T_{\gamma / \gamma}$, the solid bridging is strong enough to sustain the tensile stress generated by thermal contraction and solidification.

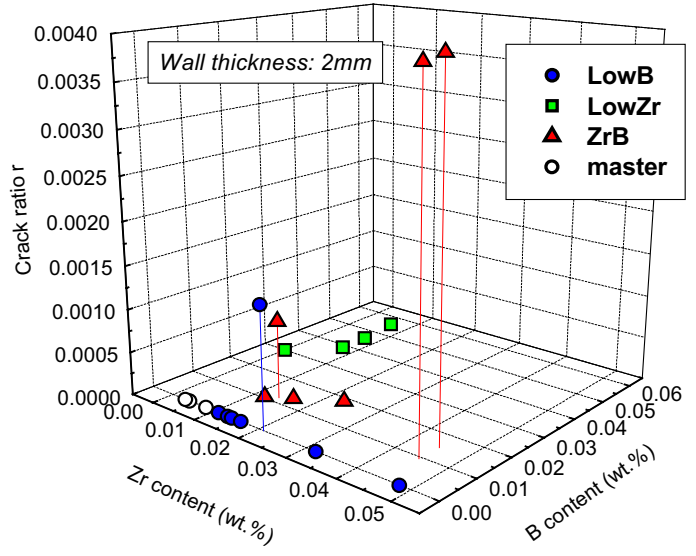

(a)

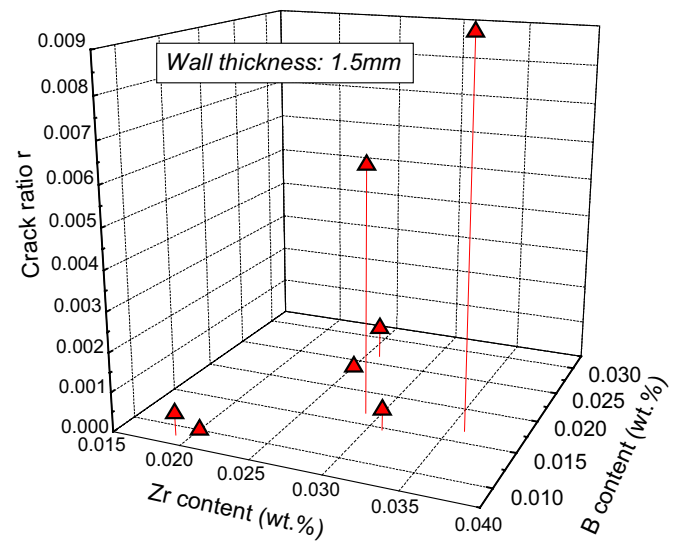

(b)

Figure 6. Results of castability trials on IN792 alloys with different $\mathrm{Zr}$ and $\mathrm{B}$ content. (a) Castability tests performed by using the ceramic mould with a wall thickness of $2 \mathrm{~mm}$. Master alloy without $\mathrm{Zr}$ and $\mathrm{B}$, and alloys containing either $\mathrm{Zr}$ or B but with very low concentration of the other element do not crack. Alloys with low B and $\mathrm{Zr}$ content also exhibits good castability. Severe crack occurred when an alloy containing relatively low B, but high $\mathrm{Zr}$ content. (b) Castability tests performed by using the ceramic mould with a wall thickness of $1.5 \mathrm{~mm}$. Narrower range of $\mathrm{Zr}$ and $\mathrm{B}$ was considered. Similar results were obtained. 


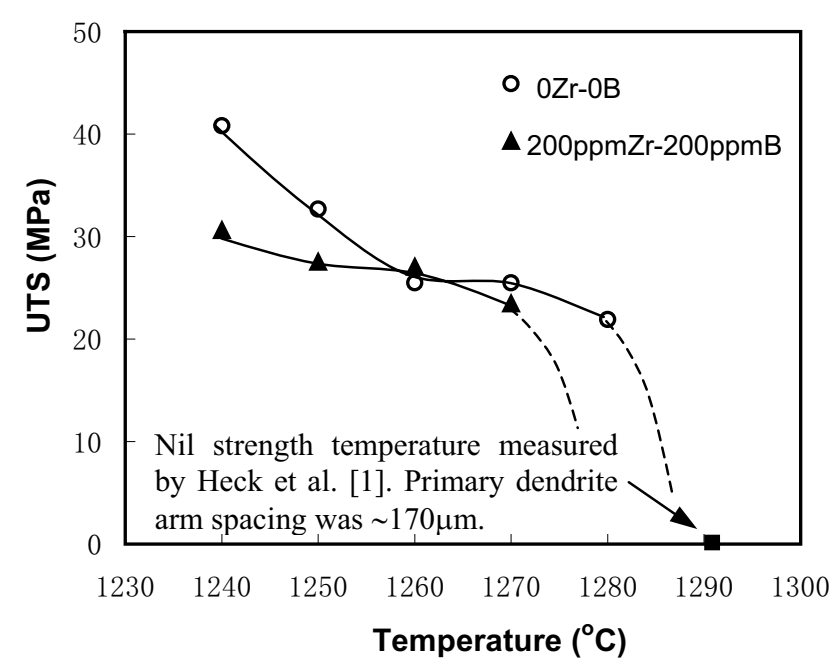

Figure 7. Preliminary results from Gleeble tests comparing the strength of the DS solid skeleton at temperatures above the solidus. The dash line indicates low stress that was not detectable by the present configuration of the Gleeble machine.

Table III. Phase Formation Temperatures $\left({ }^{\circ} \mathrm{C}\right)$ Measured from DSC in the Experimental Alloys with Different Minor Element Content. Concentrations of $\mathrm{Zr}$ and B Are Determined by X-ray Fluorescence Analysis

\begin{tabular}{|c|c|c|c|c|c|c|c|}
\hline & $\begin{array}{c}\mathrm{Zr} \\
(\mathrm{ppm})\end{array}$ & $\begin{array}{c}\mathrm{B} \\
(\mathrm{ppm})\end{array}$ & $\mathrm{T}_{\gamma}$ & $\mathrm{T}_{\mathrm{C}}$ & $\mathrm{T}_{\gamma / \gamma^{\prime}}$ & $\Delta \mathrm{T}$ & $\Delta \mathrm{T}_{\mathrm{CTR}}$ \\
\hline Master alloy & 40 & $<10$ & 1358 & 1326 & $*$ & -- & -- \\
\hline \multirow{4}{*}{ Low B alloy } & 110 & $<10$ & 1359 & 1324 & $*$ & -- & -- \\
\hline & 130 & $<10$ & 1356 & 1324 & $*$ & -- & -- \\
\hline & 160 & $<10$ & 1359 & 1324 & $*$ & -- & -- \\
\hline & 210 & $<10$ & 1357 & 1322 & $*$ & -- & -- \\
\hline \multirow{3}{*}{ Low Zr alloy } & 60 & 560 & 1357 & 1310 & 1230 & 127 & 80 \\
\hline & 70 & 390 & 1362 & 1321 & 1238 & 124 & 83 \\
\hline & 70 & 460 & 1357 & 1312 & 1234 & 123 & 78 \\
\hline \multirow{6}{*}{$\begin{array}{l}\mathrm{Zr} \text { and } \mathrm{B} \\
\text { containing } \\
\text { alloy }\end{array}$} & 120 & 106 & 1352 & 1316 & 1252 & 100 & 64 \\
\hline & 140 & 120 & 1359 & 1316 & 1248 & 111 & 68 \\
\hline & 160 & 135 & 1352 & $*$ & 1252 & 100 & -- \\
\hline & 230 & 188 & 1352 & 1310 & 1248 & 104 & 62 \\
\hline & 300 & 250 & 1349 & 1318 & 1239 & 110 & 79 \\
\hline & 310 & 147 & 1352 & 1320 & 1241 & 111 & 79 \\
\hline
\end{tabular}

* Temperature not detectable by DSC.

\section{Effect of grain boundary characteristics}

As the feeding situation is unaltered or even improved with increasing in GB misorientation, the results in Fig. 4 point to an important role of GB cohesion: in the $\Delta T_{C T R}$ where feeding is difficult, less strong bonding of secondary dendrite arms probably leads to less resistance to hot tearing.

Geometrically, since the GB interrupts the regular arrangement of secondary dendrite arms impinging upon each other, the material cohesion is less strong along the GB compared to the grain interior. This interruption may become severe as the misorientation increases. This makes GB with high misorientation a preferred site for crack initiation and propagation. Another possible mechanism is that a remaining thin liquid film at GBs that may build up due to elemental segregation prevents the secondary dendrite arms from bridging, and consequently less strength can be developed. In most cases where the GB misorientation ranges from $0^{\circ}$ to $45^{\circ}$, it was observed that the concentration of segregants increases rapidly from $0^{\circ}$ to $\sim 20^{\circ}$, and remains relatively stable at the high level [14]. Consequently, stronger segregation and probably a remaining liquid film at GB with high misorientations are expected.

\section{Effect of alloying elements}

Major alloying elements Based on a simple model, the total strain within $\Delta T_{C T R}$ for the experimental alloys studied can be calculated [10]. The measured crack ratio $r$ of different DS alloys as a function of the calculated strain $\varepsilon$ is shown in Fig. 8. It is clearly seen that the alloys such as IN792, IN792Ti3 and IN792Ti4.5 with a higher $d f / d T$ in the critical temperature range are subjected to larger strains than the alloys such as CM247 and IN792Hf2. This leads to a high cracking tendency, i.e. bad castability. It should be noted that larger strains for a specific alloy also imply larger strain rates in the present case, since $\Delta T_{C T R}$ is about the same for most of the alloys studied (see Table II).

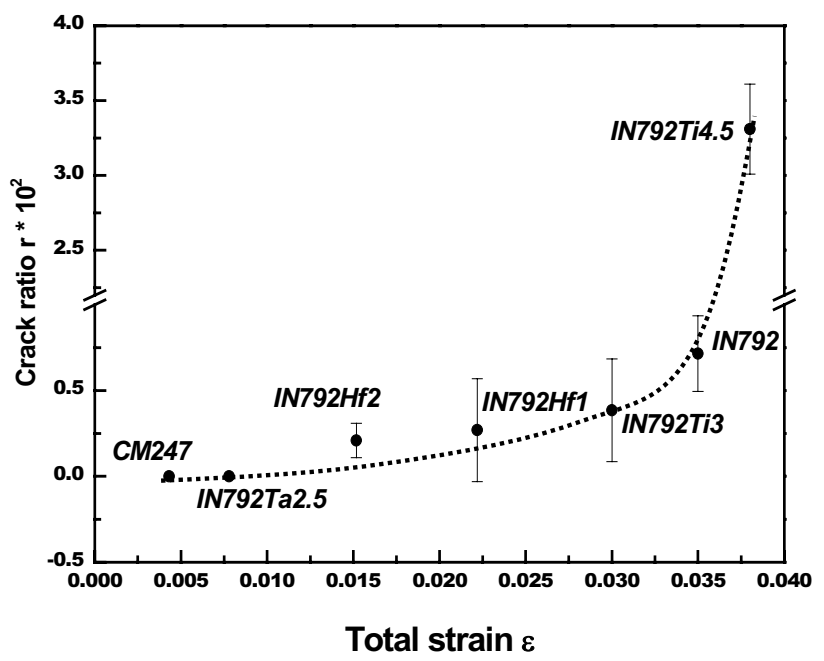

Figure 8. Measured crack ratio as a function of calculated total strain in different DS alloys.

Minor alloying elements Our present results indicate that the interaction between $\mathrm{Zr}$ and B affects the castability of IN792 dramatically. Similar results have been reported in superalloy welds: minor elements do not individually cause significant increases in heat affected zone cracking sensitivity, but when several minor elements are present at nominally high levels, their effects are additive [3].

As discussed above, the bridging of secondary arms is important within $\Delta T_{C T R}$, i.e. the strength of the solidifying skeleton determines hot tearing susceptibility. It is obvious that bridging will be affected by the way the remaining liquid is distributed. Fig. 9 is a schematic diagram, showing two possibilities. A situation is considered where the volume of remaining melt is about the same. In Fig. 9 (a) the remaining melt is present in the form of isolated 
pockets, while in Fig. 9 (b) the melt forms a continuous liquid film. Obviously, GB cohesion will be less in the film case.

The difference in melt distribution can be explained by considering the change of surface tension. It is well known that the surface tension of any solvent can be markedly reduced by the presence of relatively low levels of certain solute that are preferentially adsorbed at the surface or interface [15]. In the present case, one would expect a lowered surface tension of the residual liquid $\sigma_{\mathrm{sl}}$ when $\mathrm{Zr}$ and $\mathrm{B}$ content increases because of the enrichment of $\mathrm{Zr}$ and $\mathrm{B}$ in the liquid. When the surface tension of solid-solid bridging $\sigma_{\mathrm{ss}}=2 \sigma_{\mathrm{sl}}$, the GB could be completely wetted [Fig. 9 (b)], which results in much less solid bridging and bad castability.

$\mathrm{Zr}$ acts as a getter element in superalloys, i.e. $\mathrm{Zr}$ is traditionally used to reduce the detrimental effect of trace elements such as sulfur $[16,17]$. This particular role of $\mathrm{Zr}$ may not be as important in modern superalloys as it used to be in the past since the detrimental trace elements have been depressed to a very low level today. In fact, there has been reported that in some Ni-based superalloys, either in DS form or in equiaxed form, $\mathrm{Zr}$ does not show any beneficial effect on the mechanical properties $[18,19]$.

\section{$\underline{\text { Industrial application }}$}

The present results indicate a strategy of compositional modification to develop new Ni-based superalloys with improved castability. From an industrial point of view our results underline how important it is to carefully control the minor element content when it comes to hot tearing. Alloys containing both $\mathrm{B}$ and $\mathrm{Zr}$ apparently are to be avoided, with high $\mathrm{Zr}$ contents being particularly harmful. The results also indicate that high B content is not desirable in terms of heat treatment: coarse $\gamma / \gamma^{\prime}$ will be more difficult to dissolve if the volume fraction is high and if the acceptable heat treatment temperature is low.
From the argument above, to decrease the $\mathrm{Zr}$ content and carefully control the B content in Ni-based superalloys seems a good suggestion. However, in order to find the optimum alloy composition for commercial application, the effect of $\mathrm{B}$ and $\mathrm{Zr}$ on the mechanical properties must be considered too.

Therefore, future work will be concentrated on the mechanism of the influence of minor elements on hot tearing, and their effects on mechanical properties of DS alloys.

\section{Acknowledgments}

The author would like to thank DFG and BMBF for financial support (DFG Si 517/1-3, and BMBF 03N2011C). The grant provided by outstanding oversea talent program from Chinese Academy of Sciences is also acknowledged. The author would like to thank Prof. R. F. Singer at WTM Institute, University of Erlangen-Nürnberg, Prof. R. Bürgel at Osnabrück University of Applied Sciences, Dr. W. Eßer at Siemens KWU (Power Generation Group), and Drs. J. Grossmann and O. Lüsebrink at DPC (DonCasters Precision Castings) for many valuable discussions on the subject. The author gratefully acknowledges the support of K. C. Wong Education Foundation, Hong Kong.

\section{References}

1. K. Heck, J.R. Blackford, and R.F. Singer, "Castability of Directionally Solidified Nickel Base Superalloys," Mater. Sci. Technol., 15 (1999), 213-220.

2. J. Rösler, M. Konter, and C. Tönnes. "On the Castability of Corrosion Resistant DS-Superalloys," Superalloys 1996, ed. R.D. Kissinger, D.J. Deye, D.L. Anton, A.D. Cetel, M.V. Nathal, and T.M. Pollock (Warrendale, PA: The Metallurgical Society of AIME, 1996), 515-522.

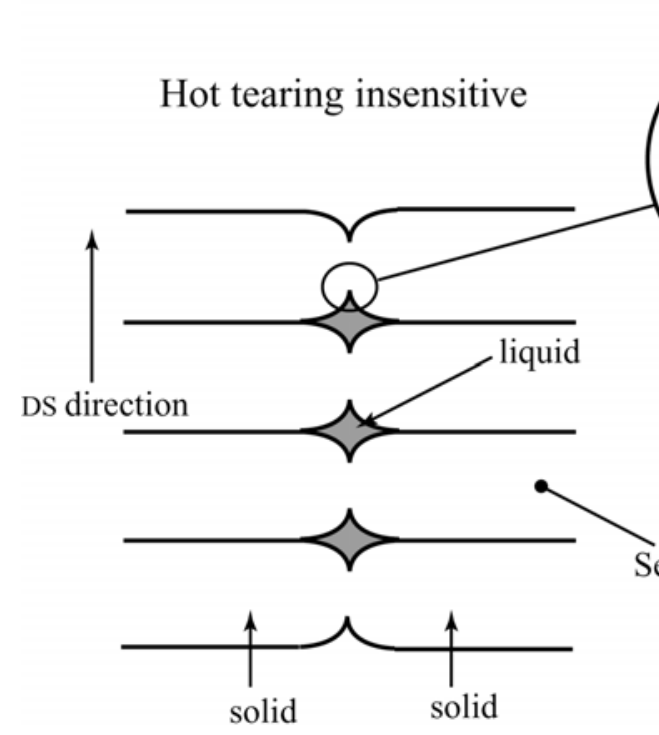

(a) Secondary dendrite arms

Figure 9. Schematic illustration of the assumed effect of $\mathrm{Zr}$ and B on mushy zone morphology of Ni-based superalloys in the final stages of DS processing. (a) In Zr and B free alloy, and alloys containing either $\mathrm{Zr}$ (and no B) or B (and no Zr), the residual liquid probably exists in form of isolated pockets at grain boundary. Therefore, bridging of secondary dendrite arms and strong boundary cohesion is favored. (b) In alloys containing $\mathrm{Zr}$ and B simultaneously, surface tension effects may cause the remaining liquid to be present as a continuous thin film

(in this case, $\sigma_{\mathrm{ss}}=2 \sigma_{\mathrm{sl}}$ ). Consequently, there is no bridging of secondary dendrite arms. The hot tearing susceptibility is very high. 
3. C. T. Sims, N. S. Stoloff, and W. C. Hagel, Superalloys II (New York, NY: John Wiley \& Sons, Inc., 1987), 118-122, 511.

4. Y. Zhu, J.F. Radavich, Z. Zheng, X. Ning, L. Lou, X. Xie, and $X$. Shi. "The Development and Long-Time Structural Stability of a Low Segregation Hf Free Superalloy DZ125L," Superalloys 2000, ed. T.M. Pollock, R.D. Kissinger, R.R. Bowman, K.A. Green, M. McLean, S. Olson, and J.J. Schirra, (Warrendale, PA: The Metallurgical Society of AIME, 2000), 329-339.

5. G.K. Sigworth, "Hot Tearing of Metals," AFS Trans., 155 (1996), 1053-1062.

6. J. Campbell, Castings (London, Butterworth-Heinemann Ltd., 1991), 219-229.

7. T.W. Clyne and G.J. Davies, "The Influence of Composition on Solidification Cracking Susceptibility in Binary Alloy Systems," Br. Foundrymen, 74 (1981), 65-73.

8. M. Rappaz, J.M. Drezet, and M. Gremaud, "A New HotTearing Criterion," Metall. Mater. Trans. A, 30A (1999), 449-455.

9. H. Ding, H.Z. Fu, Z.Y. Liu, R.Z. Chen, B.C. Liu, Z.G. Zhong, and D.Z. Tang, "Compensation of Solidification Contraction and Hot Cracking Tendency of Alloys," Acta Metall. Sinica, 33 (1997), 921-926.

10. J. Zhang and R.F. Singer, "Hot Tearing of Nickel-based Superalloys during Directional Solidification," Acta Mater., 50 (2002), 1869-1879.

11. J. Zhang and R.F. Singer, "Effect of Hafnium on Castability of Directionally Solidified Nickel-base Superalloys," $Z$. Metallkd., 8 (2002), 806-811.

12. J. Zhang and R.F. Singer, "Effect of Zr and B on Castability of Nickel-based Superalloy IN792," Metall. Mater. Trans. A, 35A (2004), 1337-1342.

13. J. Zhang and R.F. Singer, "Effect of Grain Boundary Characteristics on Castability of Nickel-base Superalloys," Metall. Mater. Trans. A, 35A (2004), 939-946.

14. P. Lejcek and S. Hofmann, "Thermodynamics and Structural Aspects of Grain Boundary Segregation," Crit. Rev. Solid State Mater. Sci., 20 (1995), 1-85.

15. B.J. Keene, "Review of Data for the Surface-tension of Pure Metals," Inter. Mater. Rev., 38 (1993), 157-192.

16. R.T. Holt and W. Wallace, "Impurities and Trace Elements in Ni-base Superalloys," Inter. Mater. Rev., 3 (1976), 1-24.

17. E. Gozlan, M. Bamberger, and S. F. Dirnfeld, "Role of Zirconium in the Phase Formation at the Interdendritic Zone in Nickel-based Superalloys," J. Mater. Sci., 27 (1992), 3869-3875.
18. Y. Xu, "Effect of Minor Elements on Microstructure and Properties of Cast Ni-base Superalloy" (Ph.D. thesis, Institute of Metal Research, Chinese Academy of Sciences, 2000), 36-40.

19. Y.X. Zhu and T.X. Zhang, "Development of Low Segregation Alloys," (Report KY85-15-06, Institute of Metal Research, Chinese Academy of Sciences, 1995), 1-7. 
